OPEN ACCESS

International Journal of

Environmental Research and

Public Health

ISSN 1660-4601

www.mdpi.com/journal/ijerph

Article

\title{
Contamination and Spatial Variation of Heavy Metals in the Soil-Rice System in Nanxun County, Southeastern China
}

\section{Keli Zhao ${ }^{1}$, Weijun Fu ${ }^{1, *}$, Zhengqian Ye ${ }^{1, *}$ and Chaosheng Zhang ${ }^{2}$}

1 School of Environmental and Resource Sciences, Zhejiang Agriculture and Forestry University, Lin'an 311300, China; E-Mail: kelizhao@zafu.edu.cn

2 Geographic Information System Centre, Ryan Institute and School of Geography and Archaeology, National University of Ireland, Galway, Ireland; E-Mail: chaosheng.zhang@nuigalway.ie

* Authors to whom correspondence should be addressed; E-Mails: fuweijun@zafu.edu.cn (W.F.); yezhq@zafu.edu.cn (Z.Y.); Tel.: +86-571-6108-1397 (W.F.); +86-571-6374-3066 (Z.Y.); Fax: +86-571-6374-0889 (W.F.).

Academic Editor: Paul B. Tchounwou

Received: 8 November 2014 / Accepted: 10 January 2015 / Published: 28 January 2015

\begin{abstract}
There is an increasing concern about heavy metal contamination in farmland in China and worldwide. In order to reveal the spatial features of heavy metals in the soil-rice system, soil and rice samples were collected from Nanxun, Southeastern China. Compared with the guideline values, elevated concentrations of heavy metals in soils were observed, while heavy metals in rice still remained at a safe level. Heavy metals in soils and rice had moderate to strong spatial dependence (nugget/sill ratios: $13.2 \%$ to $49.9 \%$ ). The spatial distribution of copper $(\mathrm{Cu})$, nickel $(\mathrm{Ni})$, lead $(\mathrm{Pb})$ and zinc $(\mathrm{Zn})$ in soils illustrated that their high concentrations were located in the southeast part. The high concentrations of cadmium $(\mathrm{Cd})$ in soils were observed in the northeast part. The accumulation of all the studied metals is related to the long-term application of agrochemicals and industrial activities. Heavy metals in rice showed different spatial distribution patterns. Cross-correlograms were produced to quantitatively determine the spatial correlation between soil properties and heavy metals composition in rice. The $\mathrm{pH}$ and soil organic matter had significant spatial correlations with the concentration of heavy metals in rice. Most of the selected variables had clear spatial correlation ranges for heavy metals in rice, which could be further applied to divide agricultural management zones.
\end{abstract}


Keywords: heavy metals; paddy soil; rice (Oryza sativa L.); spatial variation; spatial correlation

\section{Introduction}

With the rapid development of industry and increasing release of agrochemicals into the environment, the potential accumulation of heavy metals in agricultural soils has caused a growing public concern about food security worldwide [1]. Heavy metals can pose long-term environmental and health implications because of their non-biodegradability and persistence [2-4]. Recent rapid economic growth in China has led to an increasingly serious problem of heavy metal contamination in agricultural soils $[5,6]$.

Rice (Oryza sativa L.) is one of the most important agricultural crops in China. The quality of rice greatly affects human health, as consuming rice contaminated by cadmium $(\mathrm{Cd})$, lead $(\mathrm{Pb})$ and other metals can seriously deplete body stores of iron ( $\mathrm{Fe})$, vitamin $\mathrm{C}$ and other essential nutrients, leading to decreased immunological defenses, impaired psycho-social faculties and disabilities associated with malnutrition [7]. Therefore, it is of great importance to protect agricultural soils and ensure its sustainability.

A lot of work has been carried out on studying heavy metal bioavailability such as cadmium $(\mathrm{Cd})$, copper $(\mathrm{Cu})$, lead $(\mathrm{Pb})$, chromium $(\mathrm{Cr})$, zinc $(\mathrm{Zn})$, and others in paddy soils [8-11]. Most previous studies on accumulation of heavy metals were focused on special field areas (e.g., industrial and mining regions). Little information is available on heavy metal accumulation in paddy fields at regional scales, and the spatial correlation between heavy metals in soil-rice system has seldom been investigated.

The Hangzhou-Jiaxing-Huzhou (HJH) Plain is one of the main rice production areas in China. The accumulation of heavy metals in soil of the study area could either directly endanger the natural soil functions, or indirectly endanger the biosphere by bioaccumulation in the food chain, and ultimately endanger human health [12]. In the past several decades, agrochemicals (phosphorus fertilizers) and organic fertilizers (pig manure and poultry litter) have been extensively applied in this region. The use of chemical fertilizers in HJH Plain increased from $1.25 \mathrm{Mg} \cdot \mathrm{ha}^{-1}$ in 1975 to $3.23 \mathrm{Mg} \cdot \mathrm{ha}^{-1}$ in 2000 , and the use of pesticides increased from 82 to $175 \mathrm{Kg} \cdot \mathrm{ha}^{-1}$, over the same period [12]. The repeated applications of these agrochemicals potentially contributed to the accumulation of heavy metals in agricultural soils as some of these fertilizers and pesticides contain heavy metals such as $\mathrm{Cd}, \mathrm{Pb}, \mathrm{Zn} \mathrm{[6].}$ HJH Plain is an important part of the Yangtze River delta, which is one of the most rapidly developing regions in China. Since the end of the last century, this region has experienced a rapid transition from a traditionally agricultural-based economy to an industrial economy, involving the establishment of engineering, electronics and other industries, most of which produce wastes and pollutants. Therefore, it is important to understand heavy metal pollution in HJH Plain and provide scientific knowledge for agricultural policy-makers.

The main objectives of this study were: (1) to characterize heavy metal concentrations and spatial patterns of surface soil and rice grains; (2) to study the spatial dependence and relationship of heavy metals in the soil-rice system; (3) to determine the soil properties influencing the availability of heavy metals to rice. 


\section{Experimental Section}

\subsection{Study Area and Sampling Site Description}

This study was carried out in a main rice production area-Nanxun County-located in the center of HJH Plain, in north Zhejiang province, China (Figure 1). Nanxun covers an area of $716 \mathrm{~km}^{2}$ $\left(120^{\circ} 40^{\prime} \mathrm{E}\right.$ to $120^{\circ} 29^{\prime} \mathrm{E}, 30^{\circ} 38^{\prime} \mathrm{N}$ to $\left.30^{\circ} 56^{\prime} \mathrm{N}\right)$, and has a population of 0.54 million. The soil type in the study area is a typical paddy soil for aquatic rice production. The term "paddy soil" in this paper is related to land use, not to any strict definition of soil type in pedology [13]. Nanxun has a subtropical marine monsoon climate with an average annual rainfall of $1230 \mathrm{~mm}$ and mean annual temperature of $15.7^{\circ} \mathrm{C}$.

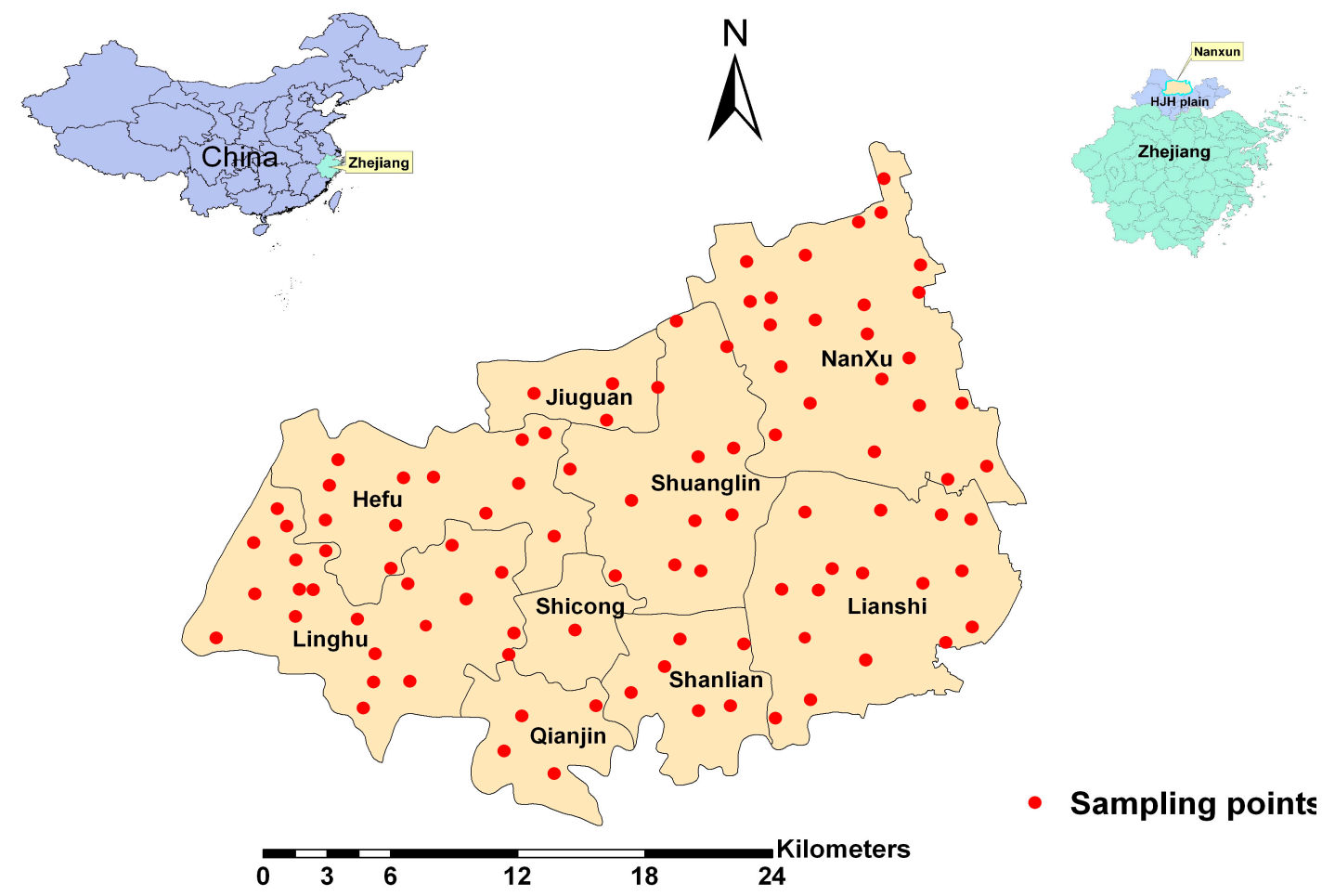

Figure 1. Location of the study area and sample sites.

A total of 100 pairs of rice grain and soil samples were collected from Nanxun County to provide a good spatial coverage of samples, based on a land use map at 1:50,000 scales. Each sample was the composite of at least $5 \mathrm{sub}$-samples within a distance of $10 \mathrm{~m}$ surrounding a specific sampling location. The rice and their corresponding soil samples (at $0-15 \mathrm{~cm}$ in depth) were collected from each site. At least $5 \mathrm{~kg}$ soil for each soil sample and $2.5 \mathrm{~kg}$ rice for each rice sample were collected. The longitudes and latitudes of the sampling points were recorded using a portable global position system (GPS). The distribution of sample locations in the study area is shown in Figure 1.

\subsection{Laboratory Analyses}

Soil samples were air-dried in the laboratory for several days at an ambient temperature. They were sieved to pass through a 2-mm nylon mesh for soil chemical and physical analyses. A portion of the 
samples were ground in an agate mortar to pass through a 0.149-mm (100 meshes) and stored in closed polyethylene bags for heavy metal concentrations and soil organic matter (SOM) analyses.

Soil properties were determined according to the standard methods [14]. Soil pH and electrical conductivity (EC) were analyzed in an aqueous suspension (1:2.5 and 1:5 soil-water ratio, respectively). Soil organic matter (SOM) was determined using the potassium dichromate wet combustion procedure. Soil particle size distribution (sand, silt and clay content) was analyzed using the hydrometer method.

Total heavy metal concentrations in soils were determined following digestion using strong acids of $\mathrm{HF}, \mathrm{HNO}_{3}$ and $\mathrm{HClO}_{4}$. Soil $\mathrm{Cd}$ concentration was measured using graphite furnace atomic absorption spectroscopy (GFAAS, PerkinElmer AA800, Waltham, MA USA) with $\mathrm{NH}_{4} \mathrm{H}_{2} \mathrm{PO}_{4}$ and $\mathrm{Mg}\left(\mathrm{NO}_{3}\right)_{2}$ as its matrix modifier, and the detection limit was $0.002 \mathrm{mg} \cdot \mathrm{L}^{-1}$. Copper, $\mathrm{Ni}, \mathrm{Pb}$ and $\mathrm{Zn}$ concentrations were determined by flame-atomic absorption spectroscopy (FAAS, PerkinElmer AA800), and the detection limits for $\mathrm{Cu}, \mathrm{Ni}, \mathrm{Pb}$, and $\mathrm{Zn}$ were $0.05,0.1,0.2$, and $0.05 \mathrm{mg} \cdot \mathrm{L}^{-1}$, respectively.

Rice grain samples were oven-dried at $105{ }^{\circ} \mathrm{C}$ for $1 \mathrm{~h}$, then at $70{ }^{\circ} \mathrm{C}$ to constant weight. Hull was removed from rice. Then the white rice samples were comminuted using a pulverizer, ground to pass through a $0.149-\mathrm{mm}$ (100 meshes) sieve and stored in closed polyethylene bags for further heavy metal concentration analysis. Rice grain samples were digested using $\mathrm{HNO}_{3}$ and $\mathrm{H}_{2} \mathrm{O}_{2}$. $\mathrm{Cd}, \mathrm{Cu}, \mathrm{Ni}$ and $\mathrm{Pb}$ concentrations were determined by GFAAS (Perkin Elmer AA800), and the detection limits for the corresponding metals were $0.002,0.014,0.07$, and $0.05 \mathrm{mg} \cdot \mathrm{L}^{-1}$. Zn concentrations were determined by FAAS (Perkin Elmer AA800) and the detection limit was $0.05 \mathrm{mg} \cdot \mathrm{L}^{-1}$. In this study, the concentrations of $\mathrm{Pb}$ in the extracted solution were below the limit of detection $\left(0.05 \mathrm{mg} \cdot \mathrm{L}^{-1}\right)$. Therefore, the $\mathrm{Pb}$ content in rice was not detected.

The accuracy of determinations was verified using the Chinese standardized reference materials (GSS-4 and GSS-15 for soil samples; GBW (E) 080684 for rice samples). All samples were measured in duplicate.

\subsection{Evaluation Method for Soil Pollution and Standard}

To evaluate heavy metal pollution in soils, single factor pollution index (SFPI) was first applied [15]. It was calculated using the following formula:

$$
P_{i}=C_{i} / S_{i}
$$

where $P_{i}$ is pollution index of pollutant $i, C_{i}$ is the measured value of $i, S_{i}$ is the guideline value of $i$. When $P_{i}$ is less than 1 , it stands for no heavy metal pollution, when $P_{i}$ is larger than 1 , it represents heavy metal pollution in the studied area.

While SFPI quantifies the individual heavy metal pollution in soils, the Nemerow multi-factor pollution index measures the overall heavy metal pollution. Nemerow multi-factor pollution can be expressed as:

$$
I=\sqrt{\left(P_{i}^{2} \operatorname{Max}+P_{i}^{2} \text { Ave }\right) / 2}
$$

where $I$ is Nemerow multi-factor pollution index at location $i, P_{i}$ Max and $P_{i}$ Ave represent the maximum and average values of SFPI, respectively. Based on Nemerow multi-factor pollution index, the environmental quality is divided into five levels, including Clean level $(I \leq 0.7)$, Precaution level 
$(0.7<I \leq 1.0)$, Light pollution level $(1.0<I \leq 2.0)$, Moderate level $(2.0<I \leq 3.0)$, Heavy Pollution level $(I>3.0)$ [15].

The background values of heavy metals from agricultural soils in Zhejiang Province [16] and Environmental Quality Standards for Soils (EQSS) in China [17] (Table 1) were used as guideline values for the assessment of heavy metal accumulation and pollution, respectively, in the study area. The EQSS includes three levels, and the second one was adopted, as the guideline values for agricultural production.

Table 1. The background values of heavy metals in soils in Zhejiang and environmental quality standard for soils in China, heavy metal standards for food safety $\left(\mathrm{mg} \cdot \mathrm{kg}^{-1}\right)$.

\begin{tabular}{|c|c|c|c|c|c|c|c|}
\hline \multirow{2}{*}{ Heavy Metals } & \multirow{2}{*}{$\begin{array}{c}\text { Background } \\
\text { Values in Zhejiang }\end{array}$} & \multirow{2}{*}{ The First Level } & \multicolumn{3}{|c|}{ The Second Level } & \multirow{2}{*}{$\frac{\text { The Third Level }}{5 \mathrm{pH}>6.5}$} & \multirow{2}{*}{$\begin{array}{l}\text { I Food Safety } \\
\text { Standards (in Rice) }\end{array}$} \\
\hline & & & $\mathrm{pH}<6.5 \mathrm{pH}$ & 6.5-7. & $.5 \mathrm{pH}>7.5$ & & \\
\hline $\mathrm{Cd}$ & 0.129 & 0.2 & 0.3 & 0.3 & 0.6 & 1.0 & 0.2 \\
\hline $\mathrm{Cu}$ & 30.54 & 35 & 50 & 100 & 100 & 400 & 10 \\
\hline $\mathrm{Ni}$ & 36.48 & 40 & 40 & 50 & 60 & 200 & 10 \\
\hline $\mathrm{Pb}$ & 30.46 & 35 & 250 & 300 & 350 & 500 & 0.2 \\
\hline $\mathrm{Zn}$ & 107.79 & 100 & 200 & 250 & 300 & 500 & 50 \\
\hline
\end{tabular}

\subsection{Geostatistical Analysis}

A variogram (or semi-variogram) is used to measure the spatial variability of a regionalized variable and provide the input parameters for the spatial interpolation of kriging. Detailed information of geostatistics is widely available in textbooks $[18,19]$. In this study, disjunctive kriging was applied. The disjunctive kriging is the principal technique to estimate the probability that the true values of soil heavy metals at an unsampled location exceed a specified threshold. It is based on the assumption that the data are a realization of a process with a second order stationary bivariate distribution. The assumption of second order stationarity means that the covariance function exists and that the variogram is therefore bounded. It is assumed that the concentration of a heavy metal is a realization of a random variable $Z(x)$, where $x$ denotes the spatial coordinates in two dimensions. If a threshold concentration $z_{c}$ is defined, marking the limit of what is acceptable, then the scale is dissected into two classes which is less and more than $z_{c}$, respectively. The value 0 and 1 can be assigned to two classes. A new binary variable, or indicator, which is denoted by $\Omega\left[Z(x) \geq z_{c}\right]$. At the sampling points the values of $Z$ are known, and so the values 0 and 1 can be assigned with certainty. Elsewhere, one can at best estimate $\Omega\left[Z(x) \geq z_{c}\right]$. In fact, it is necessary to do this in such a way that the estimate at any place $x_{0}$ approximates the conditional probability, given the data, that $Z(x)$ equals or exceeds $z_{c}$ [19].

The cross-correlogram was applied to determine spatial correlations between two variables separated by a distance $h$. At zero distance, the cross-correlogram $\rho_{12}(0)$ is equal to the Pearson correlation coefficient $[18,20]$. The cross-correlogram can be used to describe the similarity of spatial patterns, which is similar with $\rho_{12}(0)$ equal to 1 and oppositely similar with when $\rho_{12}(0)$ equals to -1 [21]. A high cross-correlogram value indicates a strong correlation. It is calculated as follows [20]: 


$$
\rho_{12}(h)=\frac{1 / n \sum_{i=1}^{n} Z_{1}\left(x_{i}\right) Z_{2}\left(x_{i}+h\right)-m_{1-h} m_{2+h}}{\sqrt{\sigma_{1-h}^{2} \sigma_{2+h}^{2}}}
$$

where $Z_{1}\left(x_{i}\right)$ is the value of variable 1 at location $\mathrm{x}_{\mathrm{i}} ; Z_{2}\left(x_{i}+h\right)$ is the value of variable 2 at a location separated by distance $h$ from location $x_{i} ; m_{1}-h$ and $m_{2}+h$ are the means of variable 1 and variable 2, respectively; $\sigma^{2}{ }_{1-h}$ and $\sigma_{2}^{2}+h$ are the variances of variable 1 and variable 2, respectively; and $n$ is the number of data pairs used to calculate the cross-correlogram at each distance $h$.

Three parameters ( $r$, range, and shape) in the cross-correlogram are important to describe the spatial correlation between two variables. The cross-correlogram value at zero distance indicates the strength of the relationship. The spatial correlation range gives the distance over which two variables are correlated. The shape of the cross-correlogram indicates how fast the correlation between two variables diminishes with distance.

\subsection{Data Analysis with Computer Software}

In linear geostatistical methods, a normal distribution for the studied variable is desired to obtain more reliable results [19]. In this study, a statistical test of the Kolmogorov-Smirnov (K-S) method together with skewness and kurtosis values were applied to evaluate the normality of data sets. The logarithmic transformation was performed on raw data sets which did not follow a normal distribution.

A specific number of values were extracted from the interpolated distribution maps by a completely randomized sampling. The density was about $1 \mathrm{~km}^{2}$ per sample, so that 750 samples were collected for cross-correlogram analysis. The descriptive parameters were calculated using SPSS $^{\circledR}$ for Windows (version 18.0). The geostatistical analysis was carried out with GS + for Win. 7.0. All maps were produced using GIS software $\operatorname{ArcMap}^{\circledR}$ (version 9.2).

\section{Results}

\subsection{Heavy Metal Concentrations in the Soil-Rice System}

The representative descriptive statistics for heavy metal concentrations in soils and rice are listed in Table 2. The total concentrations of $\mathrm{Cd}$ in soils were very variable, ranging from $0.12 \mathrm{mg} \cdot \mathrm{kg}^{-1}$ to $0.78 \mathrm{mg} \cdot \mathrm{kg}^{-1}$, with an average of $0.21 \mathrm{mg} \cdot \mathrm{kg}^{-1}$. Its kurtosis and skewness values were highly positive (Table 2), indicating the positively skewed distribution. Similar phenomena were observed for total concentrations of $\mathrm{Cu}$ and $\mathrm{Zn}$ in soils. Among the heavy metals, the total $\mathrm{Zn}$ in soils had the largest mean value $\left(106.82 \mathrm{mg} \cdot \mathrm{kg}^{-1}\right)$. The coefficient of variation $(\mathrm{CV})$ values, which were used for description of global variability (relative to local), for total $\mathrm{Cd}, \mathrm{Cu}, \mathrm{Ni}, \mathrm{Pb}$ and $\mathrm{Zn}$ in soils, were $34.96 \%, 23.97 \%, 21.00 \%, 16.08 \%$ and $28.13 \%$, respectively. All the heavy metals had moderate variability in soils. 
Table 2. Descriptive statistics for heavy metals in soils and rice $\left(\mathrm{mg} \cdot \mathrm{kg}^{-1}\right)$.

\begin{tabular}{cccccccc}
\hline Metals & Mean & SD & Min & Max & Kurtosis & Skewness & CV (\%) \\
\hline $\mathrm{Cd}_{\text {soil }}$ & 0.21 & 0.07 & 0.12 & 0.78 & $33.90(0.32)$ & $4.66(0.29)$ & 34.96 \\
$\mathrm{Cu}_{\text {soil }}$ & 31.06 & 7.45 & 18.80 & 82.31 & $22.22(0.82)$ & $3.50(0.21)$ & 23.97 \\
$\mathrm{Ni}_{\text {soil }}$ & 32.14 & 6.75 & 18.49 & 55.59 & 0.38 & 0.19 & 21.00 \\
$\mathrm{~Pb}_{\text {soil }}$ & 33.20 & 5.34 & 20.19 & 51.71 & 1.07 & 0.65 & 16.08 \\
$\mathrm{Zn}_{\text {soil }}$ & 106.82 & 30.05 & 61.55 & 266.93 & $9.30(0.37)$ & $2.33(0.39)$ & 28.13 \\
$\mathrm{Cd}_{\text {rice }}$ & 0.011 & 0.015 & 0.003 & 0.103 & $28.13(1.67)$ & $5.04(1.07)$ & 126.88 \\
$\mathrm{Cu}_{\text {rice }}$ & 2.49 & 0.74 & 1.06 & 4.23 & -0.13 & 0.22 & 29.62 \\
$\mathrm{Ni}_{\text {rice }}$ & 0.125 & 0.173 & 0.025 & 1.403 & $36.43(1.47)$ & $5.66(0.81)$ & 138.64 \\
$\mathrm{Zn}_{\text {rice }}$ & 14.28 & 2.70 & 9.45 & 21.97 & -0.21 & 0.59 & 18.93 \\
\hline
\end{tabular}

$\mathrm{Cd}_{\text {soil }}, \mathrm{Cu}_{\text {soil }}, \mathrm{Ni}_{\text {soil }}, \mathrm{Pb}_{\text {soil }}, \mathrm{Zn}_{\text {soil }}$, heavy metals in soils; $\mathrm{Cd}_{\text {rice, }}, \mathrm{Cu}_{\text {rice, }}, \mathrm{Ni}_{\text {rice, }}, \mathrm{Zn}_{\text {rice, }}$, heavy metals in rice. Kurtosis and skewness values in brackets were calculated after log-transformation. CV\% was SD in percent to the mean.

The concentrations of $\mathrm{Cd}$ in rice ranged from $0.003 \mathrm{mg} \cdot \mathrm{kg}^{-1}$ to $0.103 \mathrm{mg} \cdot \mathrm{kg}^{-1}$, with an average of $0.011 \mathrm{mg} \cdot \mathrm{kg}^{-1}$. Both $\mathrm{Cd}$ and $\mathrm{Ni}$ in rice had highly positive kurtosis and skewness values. Their $\log$-transformed data passed the normality test $\left(\mathrm{K}-\mathrm{S}_{p}>0.05\right.$, Table 2$)$. Meanwhile, they had relatively high $\mathrm{CV}$ values (Table 2). The concentrations of $\mathrm{Cu}$ ranged from $1.06 \mathrm{mg} \cdot \mathrm{kg}^{-1}$ to $4.23 \mathrm{mg} \cdot \mathrm{kg}^{-1}$. The concentrations of $\mathrm{Zn}$ varied between $9.45 \mathrm{mg} \cdot \mathrm{kg}^{-1}$ and $21.97 \mathrm{mg} \cdot \mathrm{kg}^{-1}$. Compared to the corresponding variables in soils, the heavy metals in rice had larger CV values, except for $\mathrm{Zn}$. This may be related to the influences of soil physical-chemical properties and rice genotypes on heavy metals in rice.

\subsection{The Accumulation and Pollution of Heavy Metals in Paddy Fields}

Compared with the heavy metal background values in Zhejiang Province, the average SFPI values of $\mathrm{Cd}, \mathrm{Cu}, \mathrm{Pb}$ in soils were higher than 1 (Table 3). The accumulation ratio followed the order of $\mathrm{Cd}>\mathrm{Pb}>\mathrm{Cu}>\mathrm{Zn}>\mathrm{Ni}$. For total $\mathrm{Cd}$ in soils, about $99 \%$ of the soil samples exceeded the background value, indicating obvious $\mathrm{Cd}$ accumulation in paddy soils of the study area. Compared with second grade standardized value of EQSS in China, the average SFPI values were lower than 1, indicating that the overall soil quality in the study area was safe for agricultural production. But attention should be paid to the particular locations where the concentrations of heavy metals such as $\mathrm{Cd}$ and $\mathrm{Ni}$, exceeded the guideline values (Table 3).

The Nemerow multi-factor pollution index results (Table 4) showed that $88 \%$ of the soil samples belonged to light pollution level based on background values, indicating the wide spread of heavy metal accumulation in study area. While $43 \%$ and $54 \%$ of soil samples belonged to clean and precaution levels, respectively, based on second grade standardized value of EQSS, indicating the potential heavy metal pollution in Nanxun. All the heavy metals in rice remain a safe level for human being consumption (Tables 1 and 2). 
Table 3. The evaluated results of single factor pollution index (SFPI) for heavy metals in soils.

\begin{tabular}{ccccccccc}
\hline \multirow{2}{*}{ Metals } & \multicolumn{3}{c}{ Background Value as Critical Value } & \multicolumn{4}{c}{$\begin{array}{c}\text { Second Grade Standardized Value as } \\
\text { Critical Value }\end{array}$} \\
\cline { 2 - 9 } & Mean & Min & Max & Ratio (\%) & Mean & Min & Max & Ratio (\%) \\
\hline $\mathrm{Cd}$ & 1.65 & 0.91 & 6.06 & 99.00 & 0.71 & 0.39 & 2.61 & 6.00 \\
$\mathrm{Cu}$ & 1.02 & 0.62 & 2.70 & 49.00 & 0.62 & 0.38 & 1.65 & 2.00 \\
$\mathrm{Ni}$ & 0.88 & 0.51 & 1.52 & 27.00 & 0.80 & 0.46 & 1.39 & 9.00 \\
$\mathrm{~Pb}$ & 1.09 & 0.66 & 1.70 & 69.00 & 0.13 & 0.08 & 0.21 & 0 \\
$\mathrm{Zn}$ & 0.99 & 0.57 & 2.48 & 40.00 & 0.53 & 0.31 & 1.33 & 2.00 \\
\hline
\end{tabular}

Table 4. The evaluated results of heavy metal pollution in soils (\%).

\begin{tabular}{cccccc}
\hline Standard & $\begin{array}{c}\text { Clean } \\
\boldsymbol{I}^{*}<\mathbf{0 . 7}\end{array}$ & $\begin{array}{c}\text { Precaution Level } \\
\mathbf{0 . 7}<\boldsymbol{I}<\mathbf{1}\end{array}$ & $\begin{array}{c}\text { Light Pollution } \\
\mathbf{1}<\boldsymbol{I}<\mathbf{2}\end{array}$ & $\begin{array}{c}\text { Moderate Pollution Heavy Pollution } \\
\mathbf{2}<\boldsymbol{I}<\mathbf{3}\end{array}$ & $\boldsymbol{I}>\mathbf{3}$ \\
\hline $\begin{array}{c}\text { Background } \\
\text { Value }\end{array}$ & 0 & 5 & 88 & 6 & 1 \\
$\begin{array}{c}\text { Second grade } \\
\text { Standardized } \\
\text { Value }\end{array}$ & 43 & 54 & 2 & 1 & 0 \\
\hline
\end{tabular}

$I^{*}$ is Nemerow multi-factor pollution index.

\subsection{Transfer Rate of Heavy Metals from Soil to Rice}

In order to understand the relationship of heavy metals in soil-rice system, the enrichment index (EI) was applied in this study, which was defined as the metal concentration in rice divided by that in soil [13]. Enrichment index provides a useful indication of the metal availability from soil to plants [22]. The result of EI for each heavy metal was shown in Figure 2. The average values of $\mathrm{EI}$ for $\mathrm{Cd}, \mathrm{Cu}, \mathrm{Ni}$ and Zn were $0.0829,0.0567,0.0041$ and 0.1429 , respectively, indicating the availability of heavy metals to rice was generally in the order of $\mathrm{Zn}>\mathrm{Cd}>\mathrm{Cu}>\mathrm{Ni}$. The EI varied significantly $(p<0.05)$ among heavy metals in this study.

\subsection{Spatial Structure and Spatial Distribution}

The semivariance models and their key parameters are given in Table 5. The best-fit theoretical model for the experimental semivariogram was chosen based on the highest decision coefficient value $\left(r^{2}\right)$ of all theoretical models. The $\mathrm{Cd}, \mathrm{Ni}$ and $\mathrm{Pb}$ in soils were best fit with spherical models. The $\mathrm{Cu}$ and $\mathrm{Zn}$ in soils were best fit with exponential models (Table 5). The $\mathrm{Cd}, \mathrm{Cu}, \mathrm{Ni}$ and $\mathrm{Zn}$ in rice were all best fit with exponential models (Table 5).

The "nugget/sill" ratios for $\mathrm{Cd}, \mathrm{Cu}, \mathrm{Ni}, \mathrm{Pb}$ and $\mathrm{Zn}$ in soils were $25.6 \%, 29.6 \%, 33.1 \%, 48.9 \%$ and $49.9 \%$, respectively. All the heavy metals in soils had moderate spatial dependence. The "nugget/sill" ratios for $\mathrm{Cd}, \mathrm{Cu}, \mathrm{Ni}$ and $\mathrm{Zn}$ in rice were $33.4 \%, 42.6 \%, 13.2 \%$ and $14.5 \%$, respectively (Table 5). $\mathrm{Cd}$ and $\mathrm{Cu}$ in rice had moderate dependence and $\mathrm{Ni}$ and $\mathrm{Zn}$ had strong spatial dependence. The ranges of heavy metals in soils were longer than $10 \mathrm{~km}$, except for $\mathrm{Cd}$. Compared to the $\mathrm{Ni}$ and $\mathrm{Zn}$ in rice, $\mathrm{Cd}$ and $\mathrm{Cu}$ in rice had longer ranges. 


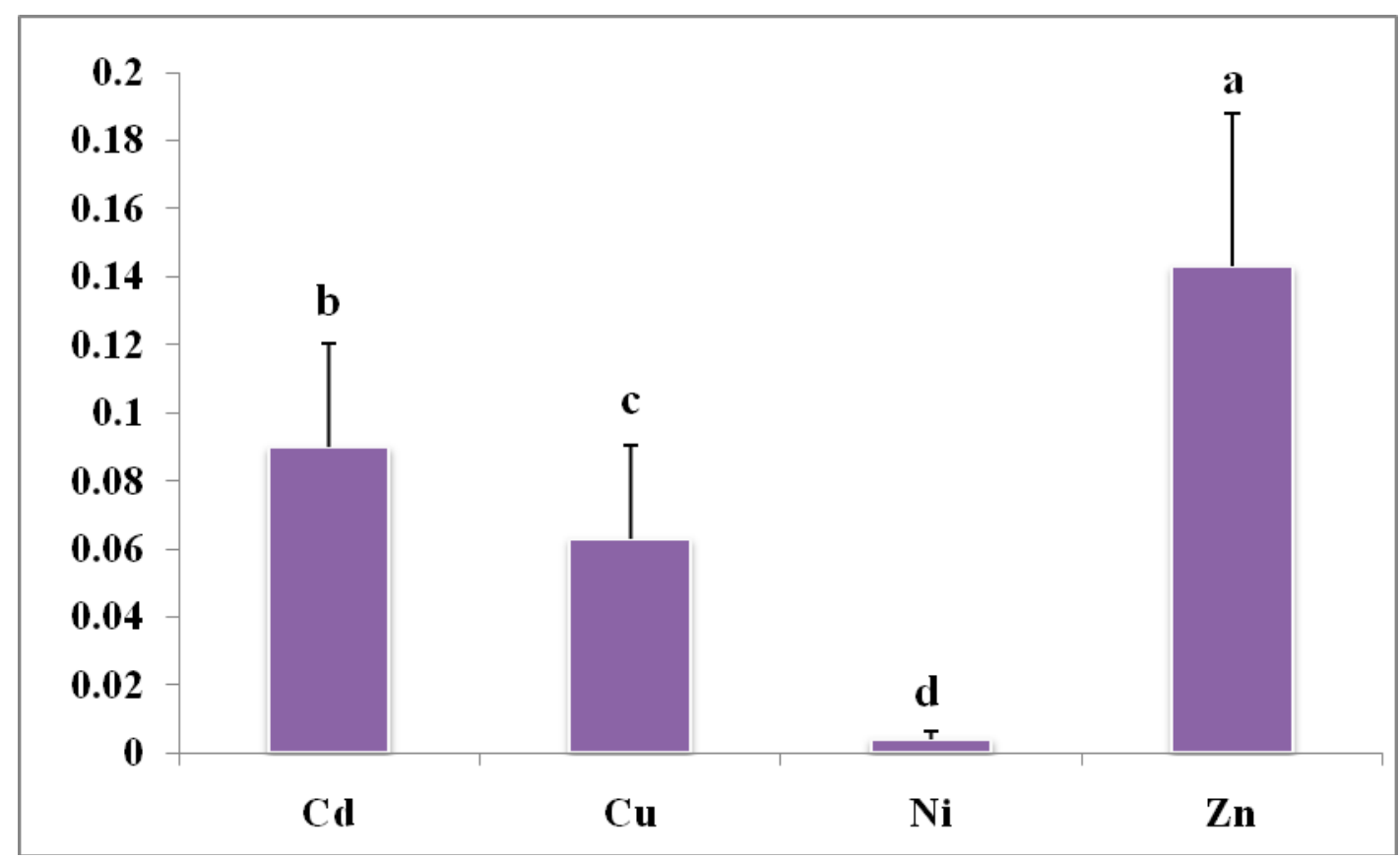

Figure 2. Enrichment index of heavy metal concentrations between soil and rice in paddy field. Different capital letters mean significantly different at the 0.05 level.

Table 5. The theoretical semivariogram models and their corresponding parameters for heavy metals in soils.

\begin{tabular}{lccccccc}
\hline Metals & Distribution Type & Models & $\begin{array}{c}\text { (Nugget) } \\
\mathbf{C}_{\mathbf{0}}\end{array}$ & $\begin{array}{c}\text { (Sill) } \\
\mathbf{C}_{\mathbf{0}}+\mathbf{C}\end{array}$ & $\begin{array}{c}\text { (Nugget/Sill \%) } \\
\mathbf{C}_{\mathbf{0}} /\left(\mathbf{C}_{\mathbf{0}}+\mathbf{C}\right)\end{array}$ & $\begin{array}{c}\text { Range } \\
\mathbf{A}(\mathbf{k m})\end{array}$ & $\boldsymbol{R}^{\mathbf{2}}$ \\
\hline $\mathrm{Cd}_{\text {soil }}$ & Log-normal & Spherical & 0.011 & 0.043 & 25.6 & 0.80 & 0.986 \\
$\mathrm{Cu}_{\text {soil }}$ & Log-normal & Exponential & 0.014 & 0.047 & 29.6 & 31.68 & 0.972 \\
$\mathrm{Ni}_{\text {soil }}$ & Normal & Spherical & 18.50 & 55.82 & 33.1 & 21.07 & 0.960 \\
$\mathrm{~Pb}_{\text {soil }}$ & Normal & Spherical & 15.91 & 32.55 & 48.9 & 22.43 & 0.876 \\
$\mathrm{Zn}_{\text {soil }}$ & Log-normal & Exponential & 0.030 & 0.059 & 49.9 & 13.26 & 0.796 \\
$\mathrm{Cd}_{\text {rice }}$ & Log-normal & Exponential & 0.252 & 0.775 & 33.4 & 21.33 & 0.824 \\
$\mathrm{Cu}_{\text {rice }}$ & Normal & Exponential & 0.386 & 0.907 & 42.6 & 12.70 & 0.892 \\
$\mathrm{Ni}_{\text {rice }}$ & Log-normal & Exponential & 0.050 & 0.380 & 13.2 & 3.93 & 0.828 \\
$\mathrm{Zn}_{\text {rice }}$ & Normal & Exponential & 1.06 & 7.31 & 14.5 & 4.59 & 0.913 \\
\hline
\end{tabular}

$\mathrm{Cd}_{\text {soil }}, \mathrm{Cu}_{\text {soil }}, \mathrm{Ni}_{\text {soil }}, \mathrm{Pb}_{\text {soil }}, \mathrm{Zn}_{\text {soil }}$, heavy metals in soils; $\mathrm{Cd}_{\text {rice }}$ ' $\mathrm{Cu}_{\text {rice, }}, \mathrm{Ni}_{\text {rice, }}, \mathrm{Zn}_{\text {rice, }}$, heavy metals in rice.

The $\mathrm{Cu}, \mathrm{Ni}, \mathrm{Pb}$ and $\mathrm{Zn}$ in soils had similar spatial distribution patterns, with high concentrations located in the south-east and south-west parts of the study area, and low concentrations in the center (Figure 3). Compared to other heavy metals, $\mathrm{Cd}$ in soils showed a different spatial pattern. Its high concentration values were observed in the northeast part of Nanxun, with some small scale patterns of medium and low concentrations, which were in line with its short range in the semivariogram model. 

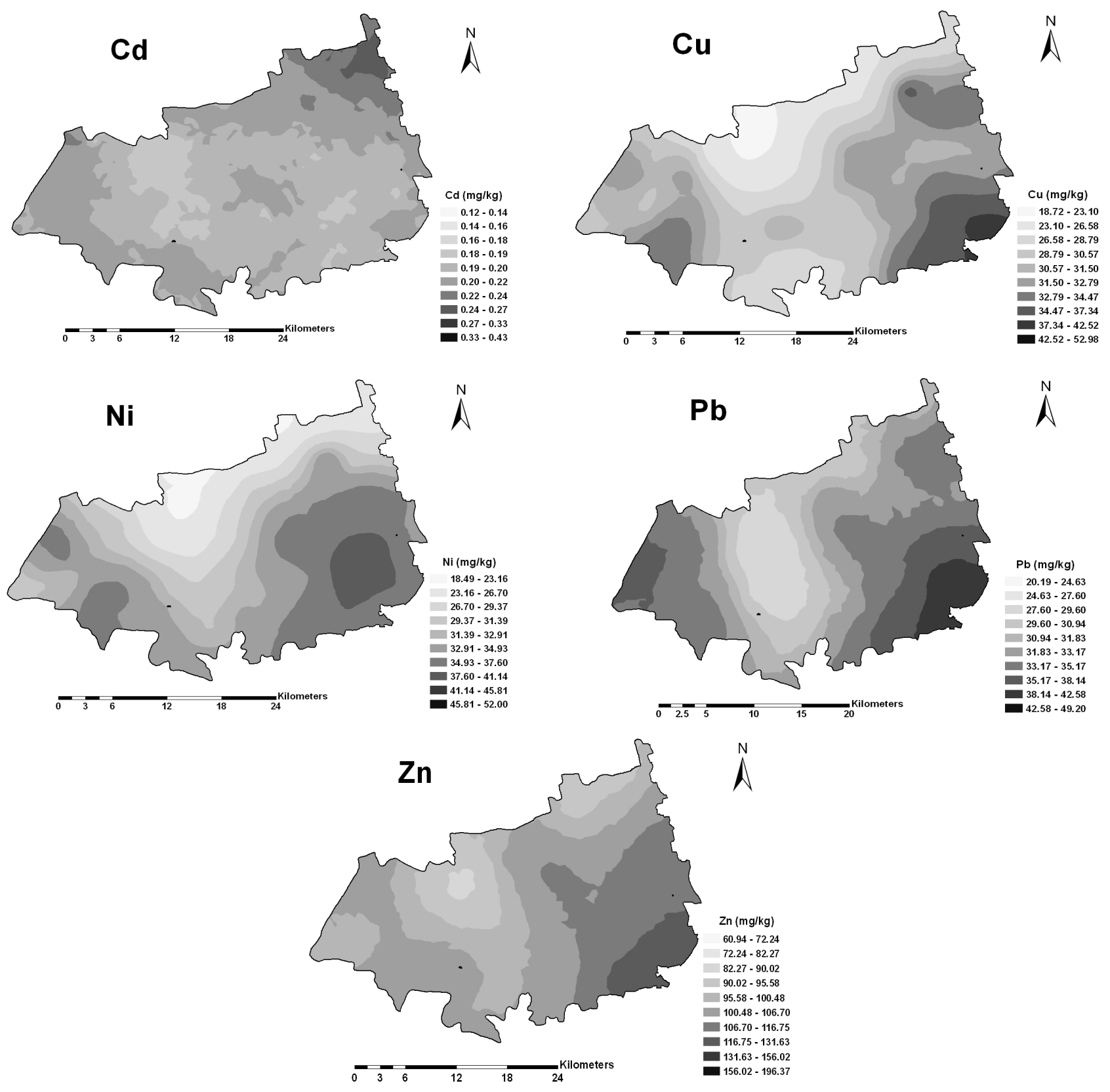

Figure 3. Spatial distribution maps of heavy metals in soils.

The spatial distribution of $\mathrm{Cd}$ in rice showed a north-to-south trend with high concentrations located in the north and low concentrations in the south (Figure 4). Copper and Ni in rice shared similar spatial patterns with high values in the northeast and low values in the southwest part. Zinc in rice showed high concentrations in the northwest part. Meanwhile, $\mathrm{Cd}$ and $\mathrm{Cu}$ in rice showed large spatial patches while $\mathrm{Ni}$ and $\mathrm{Zn}$ in rice showed small spatial patches. Meanwhile, the estimated probability of excess for $\mathrm{Cd}, \mathrm{Cu}, \mathrm{Ni}$ and $\mathrm{Zn}$, defined by the thresholds in Table 1, was kriged by disjunctive kriging and given in Figure 5 ( $\mathrm{Cd}$ and $\mathrm{Ni}$ as examples). 

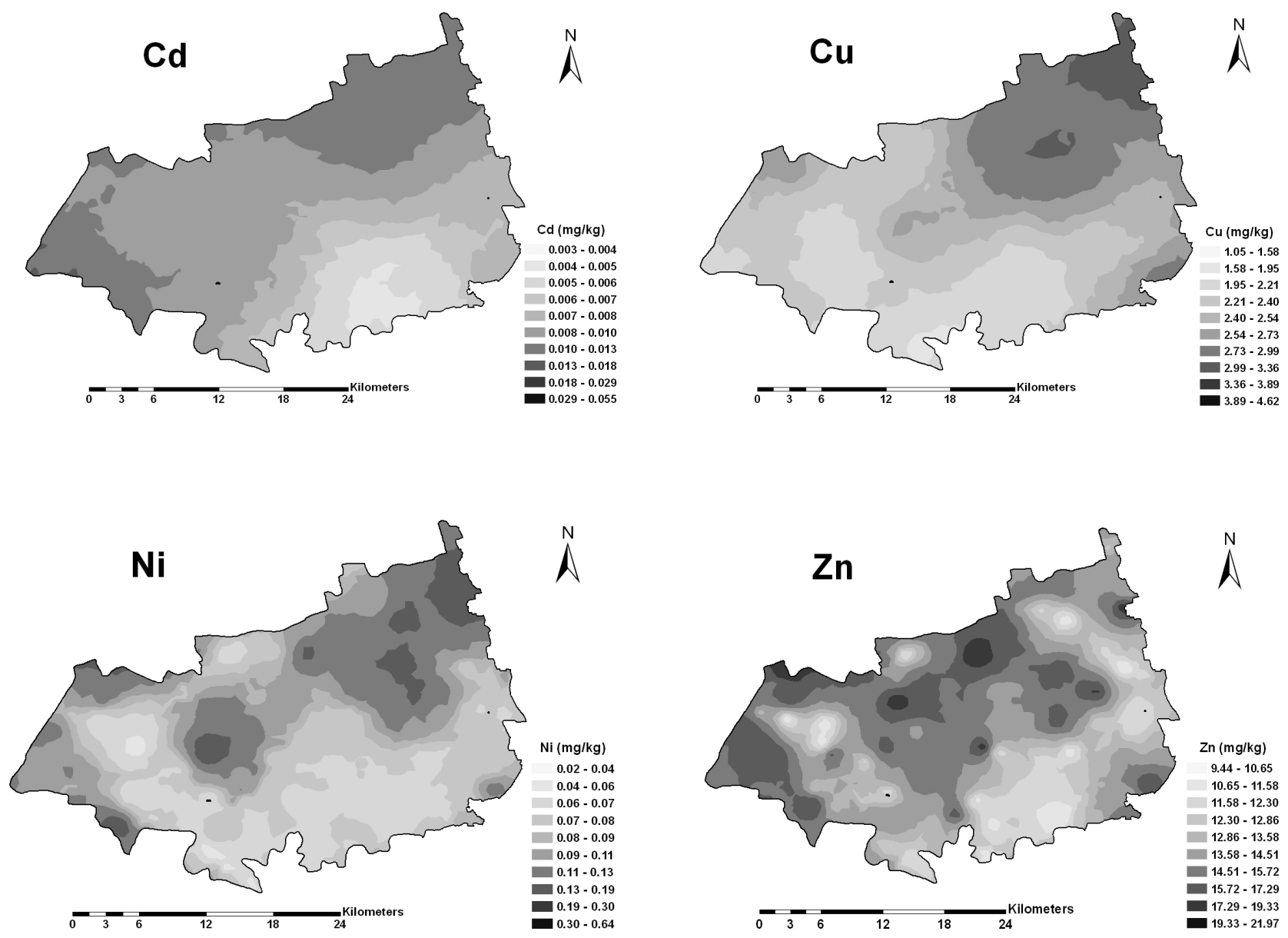

Figure 4. Spatial distribution maps of heavy metals in rice.
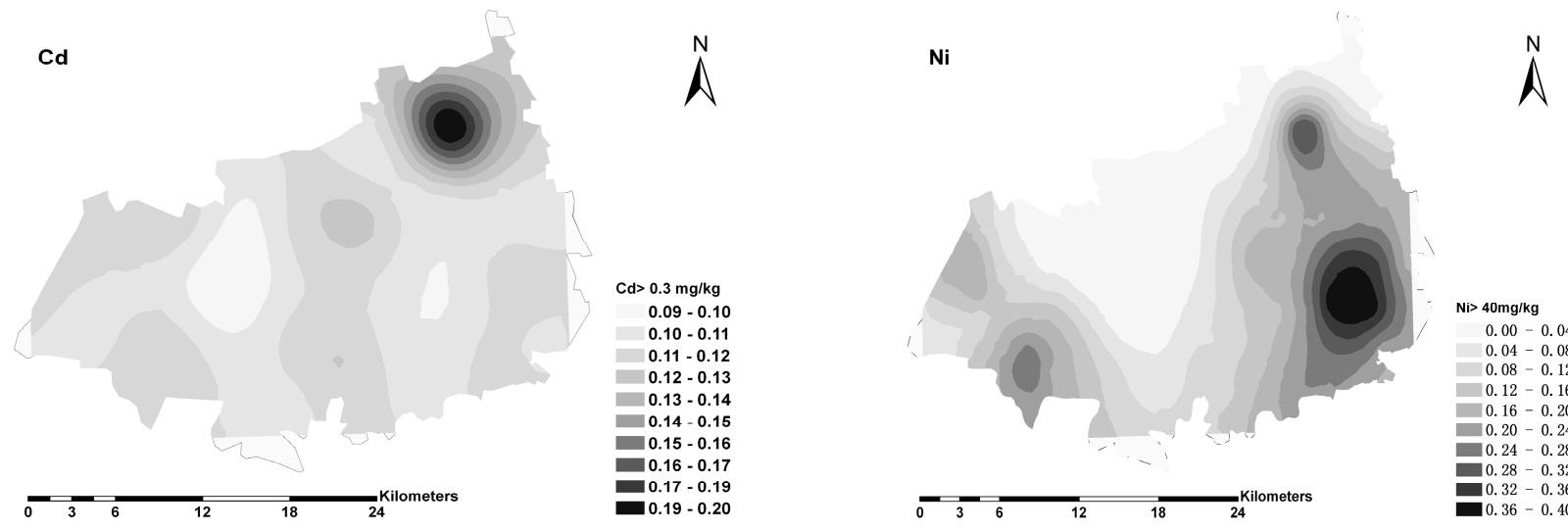

Figure 5. The estimated probability map of $\mathrm{Cd}$ and $\mathrm{Ni}$.

For soil $\mathrm{Cd}$, the map showed that the areas with high risk were mainly located in northeast part of Nanxun county, where the estimated probability $\Omega[\mathrm{Cd} \geq 0.3 \mathrm{mg} / \mathrm{kg}]$ reached $0.19-0.2$. The probability map of $\mathrm{Ni}$ exceeding the guide value $40 \mathrm{mg} / \mathrm{kg}$ exhibited many risk patches. Especially, the highest risk areas were distributed in southeastern part of the study area. Compared to $\mathrm{Cd}$ and $\mathrm{Ni}$, the probability of excess for soil $\mathrm{Cu}$ and $\mathrm{Zn}$ were relevantly low (not shown). 


\subsection{Spatial Correlation between Heavy Metals in Rice and Soil Properties}

In order to understand the potential effects of total soil heavy metals and soil properties on the availability of heavy metals to rice, cross-correlograms were produced to quantitatively determine their spatial correlations (Figure 6).
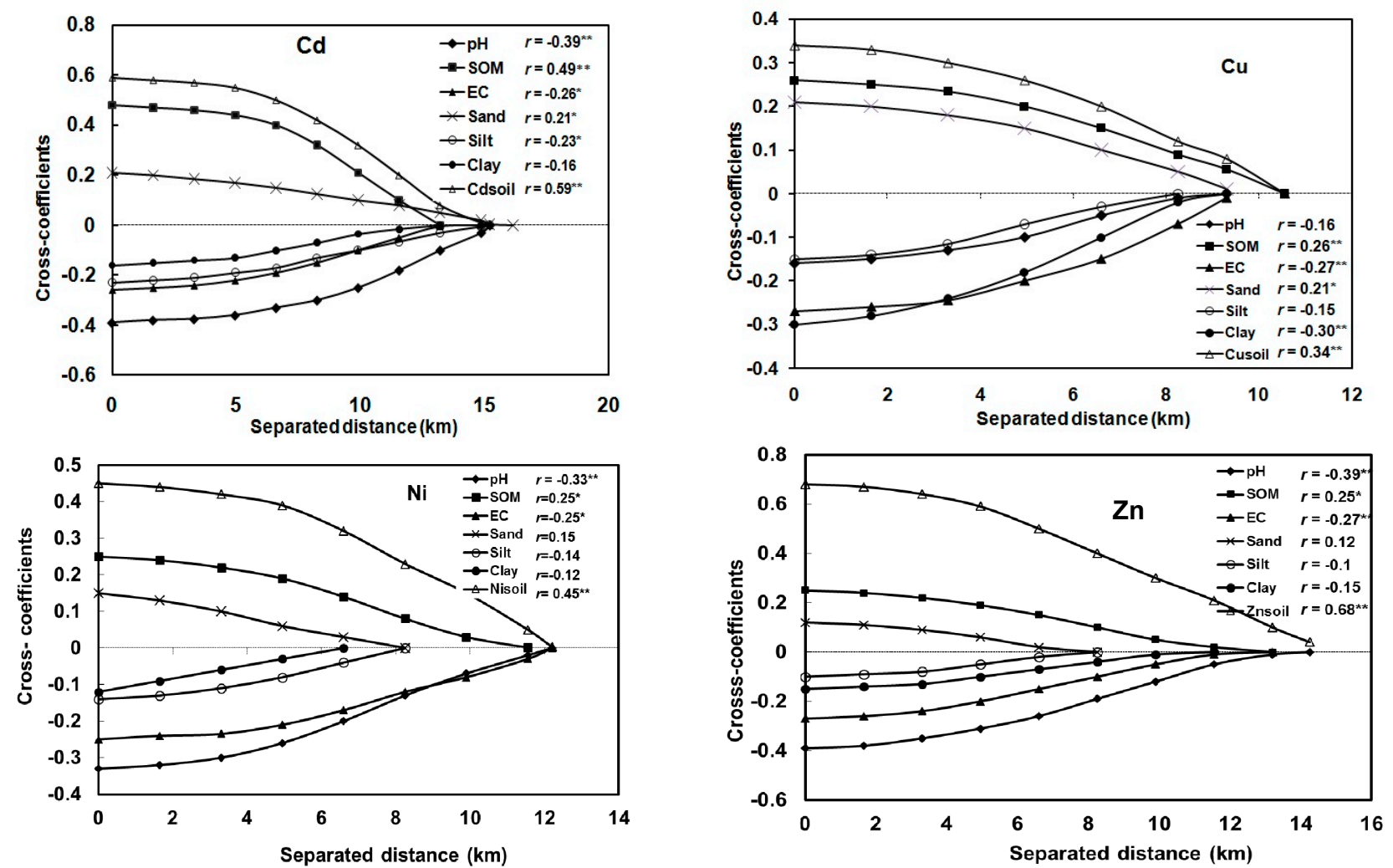

Figure 6. Cross-correlograms for each heavy metal between heavy metal in rice and soil properties, total heavy metal in soil. (** Correlation is significant at the 0.01 level; * correlation is significant at the 0.05 level).

The maximum cross-correlogram values were observed at 0 distance, which are equal to the Pearson's correlation coefficients ( $r$ values). Heavy metals in rice were all positively spatially correlated with SOM, sand contents, corresponding heavy metals in soils, and negatively spatially correlated with soil $\mathrm{pH}, \mathrm{EC}$, silt and clay contents. In the cross-correlogram for $\mathrm{Cd}$, compared to soil texture (sand, silt and clay), the $\mathrm{pH}, \mathrm{SOM}$ and $\mathrm{EC}$ had stronger cross-correlations with the $\mathrm{Cd}$ in rice. The similar phenomena were observed in the cross-correlograms for Ni and $\mathrm{Zn}$. All the heavy metals in rice had significant spatial correlation with their corresponding counterparts in soil, among which element $\mathrm{Zn}$ had the strongest cross-correlation. Meanwhile, most of the soil properties had a clear spatial correlation range with heavy metals in rice. As the distance increased, the cross-correlogram values gradually decreased to 0 (Figure 6). Compared to other soil properties, $\mathrm{pH}$ generally had the longest spatial correlation distance with heavy metals in rice. 


\section{Discussion}

Compared to the background values of heavy metals in soils (Table 1), $\mathrm{Cd}, \mathrm{Cu}, \mathrm{Pb}$ and $\mathrm{Zn}$ (Tables 3 and 4) were obviously enriched in the study area. In order to improve the yield of rice grain, a large amount of chemical fertilizers (increased from $1.25 \mathrm{~T} \cdot \mathrm{ha}^{-1}$ to $3.23 \mathrm{~T} \cdot \mathrm{ha}^{-1}$ ) has been applied for the past three decades. This amount of fertilizers exceeded the maximum guideline for safe agricultural production [23]. It was found that the concentrations of $\mathrm{Cd}, \mathrm{Cu}, \mathrm{Pb}$ and $\mathrm{Zn}$ in chemical fertilizers were $0.0005-0.5 \mathrm{mg} \cdot \mathrm{kg}^{-1}, 0.41-11.6 \mathrm{mg} \cdot \mathrm{kg}^{-1}, 0.0008-0.93 \mathrm{mg} \cdot \mathrm{kg}^{-1}$ and $4.87-348.2 \mathrm{mg} \cdot \mathrm{kg}^{-1}$, respectively [24]. In this study, all samples were collected from agricultural fields which received chemical fertilizers, while there was no fertilizer application in the area where background values of heavy metals in soils were determined. Meanwhile, farmers applied pesticides in order to control plant diseases and insects. For the single cropping of rice, repeated pesticide applications ( 8 times) were carried out during the growing seasons [25]. Plumlee [26] reported that excessive usage of pesticides and herbicides could lead to $\mathrm{Cu}$, $\mathrm{As}, \mathrm{Pb}$ and $\mathrm{Zn}$ accumulation in topsoils of agricultural fields. The long-term application of fertilizers and pesticides may be one of the main sources for heavy metal accumulation in soils in the study area [6,12].

In general, heavy metal concentrations in rice remained at a safe level in the study area (Table 2). The concentrations of $\mathrm{Cd}$ in rice ranged from $0.003 \mathrm{mg} \cdot \mathrm{kg}^{-1}$ to $0.103 \mathrm{mg} \cdot \mathrm{kg}^{-1}$, which were lower than the guideline value for food safety (Table 1). Heavy metal concentrations in rice were comparable with those in the areas under traditional agricultural management $[13,27]$, but lower than those in the areas influenced by industrial activities such as an e-waste dismantling areas [28], or irrigated with sewage [29]. Attention should be paid to the locations where heavy metals in soils exceeded the second level of EQSS, as heavy metal concentrations in rice of these areas were also relatively high.

The availability of heavy metals to rice was significantly $(p<0.05)$ different among heavy metals. These results were in line with other studies. Kashem and Singh [30] reported that the accumulation of $\mathrm{Cd}$ and $\mathrm{Zn}$ was higher than that of $\mathrm{Ni}$ in rice. Heavy metal concentrations of $\mathrm{Cd}$ and $\mathrm{Zn}$ in rice increased faster with increasing metal concentrations in paddy soil than that of $\mathrm{Cu}$ and $\mathrm{Pb}[31]$. The EI value of $\mathrm{Zn}$ was higher than that of $\mathrm{Cd}$ (Figure 2). This finding was different with a previous study [13]. This was probably related to the different rice types, as the rice genotypes were the main factors influencing the transfer and bioavailability of heavy metals in the soil-rice system $[32,33]$. The main rice type in Nanxun County was Japonica Rice, while the main rice type in Wenling was Hybrid Rice [13]. Zeng et al. [33] have reported that Hybrid Rice accumulated more heavy metals than Japonica Rice under the same soil conditions.

The parameters of semivariogram models provide information of the spatial variability, including intrinsic variability and extrinsic variability. The intrinsic variability is considered to be mainly from natural variation such as parent material, while extrinsic variability is mainly due to human activities $[6,34,35]$. As a rough guide, the variable is considered to have a strong spatial dependence if the "nugget/sill" ratio is $<25 \%$, a moderate spatial dependence if this ratio is between $25 \%$ and $75 \%$, and weak spatial dependence if the ratio is $>75 \%$ [22]. Usually, strong spatial dependence of soil variables may be controlled by intrinsic factors, and weak spatial dependence may indicate that variability is controlled more by extrinsic factors [36,37]. Heavy metals in soils were moderately spatially dependent in this study (Table 5). This was attributed to both intrinsic factors such as soil texture and extrinsic factors such as agricultural activities, industrial sources and other anthropogenic 
activities. The results were in line with previous studies on the spatial structures of heavy metals in agriculture soils [34,35,38]. In geostatistical theory, the range of a semivariogram is the measure of spatial extension within which autocorrelation exists [39]. The range values of heavy metals in soil (except $\mathrm{Cd}$ ) were longer than $10 \mathrm{~km}$, which were much longer than the sampling interval. This suggested that the current sampling design is good enough to reveal spatial distribution features of heavy metals in soils.

The kriging estimates can be mapped to reveal the overall trend of the data [40]. Maps provide useful visual display of the spatial variability and can be used to represent and summarize soil properties [41]. As shown in Figure 3, the high concentrations for $\mathrm{Cu}, \mathrm{Ni}, \mathrm{Pb}$ and $\mathrm{Zn}$ were located in the southeast part of the study area, where the paddy fields were contaminated to some degree (Table 4). Based on our survey, it was clearly found that many industries are distributed in the study area, which included mechanical and electric production, leather and plastic production, dye, and others [42]. These industries are the likely sources for the extrinsic factors leading to these high concentrations of heavy metals in soils. There were a few small-scale patterns of high $\mathrm{Cd}$ concentrations in the north part of the study area, which was related to industrial point pollution sources such as coal-fired heating station and Ni-Cd battery production plants.

Compared with the spatial distribution patterns of heavy metals in soils, differences were observed for the corresponding heavy metals in rice (Figures 3 and 4), indicating that other factors may also play an important role in the transfer of heavy metals from soils to rice. Cross-correlograms further quantified the spatial correlation between the heavy metals in rice and soil properties, and provided information for delineating the size of potential management zones. Figure 5 revealed that high SOM would increase the accumulation and availability of heavy metals in rice $(p<0.01$ or $p<0.05)$. In contrast, high soil $\mathrm{pH}$ and $\mathrm{EC}$ contents decreased the accumulation and availability. Furthermore, $\mathrm{pH}$ and SOM showed higher spatial correlation with heavy metals in rice, except for $\mathrm{Cu}$. Soil $\mathrm{pH}$ influenced the dissolution of heavy metals, particularly in acid paddy field [43]. Low pH may result in increased solubility and high availability of heavy metals for rice [13]. Previous studies investigated the effect of soil properties on metals uptake by plants $[6,44]$. Soil $\mathrm{pH}$ is a significant factor controlling uptake of heavy metals, and above all, is perhaps the most important factor $[31,45]$. The SOM was another soil property that influenced the distribution of heavy metals in soils and the bioavailability of heavy metals to rice. The effect of SOM on the availability of heavy metals could be due to lower solubility of heavy metals in soils, and the availability of heavy metals decreased with increasing SOM [30,33]. Soil EC also played a role in the availability of heavy metals in the soil-rice system, as negative correlations were found between EC and heavy metals. The observed cross-correlograms (Figure 5) indicated that soil properties did influence the transfer of heavy metals from the soils to rice, which was not limited to individual sites but encompassed to all paddy fields. The influence of soil properties on the availability of heavy metals in rice varied among different heavy metals. Compared to other heavy metals, $\mathrm{Cu}$ in rice was weakly correlated with soil $\mathrm{pH}$ and $\mathrm{OM}$, implying that the transfer of $\mathrm{Cu}$ in paddy soils and rice may be affected by other factors, which needs further studies. 


\section{Conclusions}

Based on the guideline values for heavy metal pollution, the paddy fields of Nanxun showed $\mathrm{Cd}$, $\mathrm{Cu}, \mathrm{Ni}$ and $\mathrm{Zn}$ contaminations, while the rice remained at a safe level. The long-term application of fertilizers and pesticides, and industrial activities were the main pollution sources in the study area. Soil properties, especially $\mathrm{pH}$ and SOM, played an important role in the availability of most heavy metals to rice plants in the paddy fields. Heavy metals in soils and rice had clear spatial patterns. Such information, combined with soil properties, could be used for rational site-specific management in paddy fields.

\section{Acknowledgments}

This work was financially supported by the National Natural Science Foundation of China (No. 41201538, 41201323), the Public Welfare Project of Science and Technology Department of Zhejiang Province (2013C33016) and Startup Foundation for Introducing Talents of Zhejiang Agriculture and Forestry University (2010FR091).

\section{Author Contributions}

Keli Zhao conducted this research and wrote this manuscript. Weijun Fu and Zhengqian Ye designed this experiment and provided strategic direction for the development of manuscript. Chaosheng Zhang contributed to data analysis and development of manuscript.

\section{Conflicts of Interest}

The authors declare no conflict of interest.

\section{References}

1. Wong, S.C.; Li, X.D.; Zhang, G.Q.; Min, Y.S. Heavy metals in agricultural soils of the Pearl River Delta, South China. Environ. Pollut. 2002, 119, 33-44.

2. Adriano, D.C. Trace Elements in Terrestrial Environments: Biogeochemistry, Bioavailability, and Risks of Metals; Springer: New York, NY, USA, 2001.

3. Huang, P.M.; Gobran, G.R. Biogeochemistry of Trace Elements in the Rhizosphere; Elsevier: Amsterdam, The Netherlands, 2005.

4. Zhao, K.L.; Liu, X.M.; Zhang, W.W.; Xu, J.M.; Wang, F. Spatial dependence and bioavailability of metal fractions in paddy fields on metal concentrations in rice grain at a regional scale. J. Soil Sediment. 2011, 11, 1165-1177.

5. Chen, H.M.; Zheng, C.R.; Tu, C.; Zhu, Y.G. Heavy metal pollution in soils in China: Status and countermeasures. AMBIO 1999, 28, 130-134.

6. Huang, S.S.; Liao, Q.L.; Hua, M.; Wu, X.M.; Bi, K.S.; Yan, C.Y.; Chen, B.; Zhang, X.Y. Survey of heavy metal pollution and assessment of agricultural soil in Yangzhong district, Jiang Su Province, China. Chemosphere 2007, 67, 2148-2155. 
7. Liu, H.Y.; Probst, A.; Liao, B.H. Metal contamination of soils and crops affected by the Chenzhou lead/zinc mine spill (Hunan, China). Sci. Total. Environ. 2005, 339, 153-166.

8. Haldar, M.; Mandal, L.N. Effect of phosphorus and zinc on the growth and phosphorus zinc, copper, iron and manganese nutrition of rice. Plant Soil 1981, 59, 415-425.

9. Wang, Q.R.; Cui, Y.S.; Liu, X.M.; Dong, Y.T.; Christie, P. Soil contamination and plant uptake of heavy metals at polluted sites in China. J. Environ. Sci. Health. A. 2003, 38, 823-838.

10. Cheng, W.D.; Zhang, G.P.; Yao, H.G.; Dominy, P.; Wu, W.; Wang, R.Y. Possibility of predicting heavy-metal contents in rice grains based on DTPA-extracted levels in soil. Commun. Soil Sci. Plan. 2004, 35, 2731-2745.

11. Li, Z.W.; Li, L.; Pan, G.X.; Chen, J. Bioavailability of Cd in a soil-rice system in China: Soil type vs. genotype effects. Plant Soil 2005, 271,165-173.

12. Liu, X.M.; Wu, J.J.; Xu, J.M. Characterizing the risk assessment of heavy metals and sampling uncertainty analysis in paddy field by geostatistics and GIS. Environ. Pollut. 2006, 141, $257-264$.

13. Zhao, K.L.; Liu, X.M.; Xu, J.M.; Selim, H.M. Heavy metal contaminations in a soil-rice system: Identification of spatial dependence in relation to soil properties of paddy fields. J. Hazard. Mater. 2010, 181, 778-787.

14. Agricultural Chemistry Committee of China. Conventional Methods of Soil and Agricultural Chemistry Analysis; Science Press: Beijing, China, 1983. (In Chinese)

15. China Green Food Development Center. Environmental Quality Assessment for Green Food Production Program; Science Press: Beijing, China, 1994. (In Chinese)

16. Zhejiang Soil Survey Office. Zhejiang Soils; Zhejiang Technology Press: Hangzhou, China, 1994; pp. 556-562. (In Chinese)

17. Ministry of Environmental Protection of China. Environmental Quality Standard for Soils; China Environment Press: Beijing, China, 2005. (In Chinese)

18. Goovaerts, P. Geostatistics for Natural Resources Evaluation; Oxford University Press: New York, NY, USA, 1997.

19. Webster, R.; Oliver, M.A. Geostatistics for Environmental Scientists; Wiley: Chichester, UK, 2001.

20. Stein, M.B.; Walker, J.R.; Hazen, A.L.; Forde, D.R. Full and partial posttraumatic stress disorder: Findings from a community survey. Am. J. Psychiatry 1997, 154, 1114-1119.

21. Deutsch, C.V.; Journel, A.G. Geostatistical Software Library and User's Guide; Oxford University Press: New York, NY, USA, 1998.

22. Cambardella, C.A.; Moorman, A.T.; Novak, J.M.; Parkin, T.B.; Karlen, D.L.; Turco, R.F.; Konopka, A.E. Field-scale variability of soil properties in central Iowa soils. Soil Sci. Soc. Am. J. 1994, 58, 1501-1511.

23. Gao, C.; Zhang, T.L. Environmental management: Options practiced in Europe to mitigate agricultural nutrient pollution of ground and surface water. Rural Eco-Environ. 1999, 15, 50-53. (In Chinese)

24. Wang, Q.C.; Ma, Z.W. Heavy metals in chemical fertilizer and environmental risks. Rural Eco-Environ. 2004, 20, 62-64. (In Chinese) 
25. Quan, W.M.; Shen, J.F.; Dong, M.Q.; Zhang, Q.L.; Lu, Z.M.; Sheng, B.L. Treatment measures on agricultural non-point pollution in Hang-Jia-Hu Plain. Rural Environ. Devel. 2002, 2, 22-24. (In Chinese)

26. Plumlee, K.H. Toxicosis from agricultural chemicals. Clin. Tech. Equine. Pract. 2002, 1, 94-97.

27. Fu, J.J.; Zhang, A.Q.; Wang, T.; Qu, G.B.; Shao, J.J.; Yuan, B.; Wang, Y.W.; Jiang, G. Influence of E-waste dismantling and its regulations: temporal trend, spatial distribution of heavy metals in rice grains, and its potential health risk. Environ. Sci. Technol. 2013, 47, 7427-7445.

28. Fu, J.J.; Zhou, Q.F.; Liu, J.M.; Liu, W.; Wang, T.; Zhang, Q.H.; Jiang, G.B. High levels of heavy metals in rice (Oryza sativa L.) from a typical E-waste recycling area in southeast China and its potential risk to human health. Chemosphere 2008, 71, 1269-1275.

29. Cui, X.T.; Luan, W.L.; Shi, S.J.; Li, S.M.; Song, Z.F.; Ma, Z.S. Soil heavy metal pollution assessment in the sewage irrigation region of Shijiazhuang city. Earth Environ. 2010, 38, 36-42. (in Chinese)

30. Kashem, M.A.; Singh, B.R. Metal availability in contaminated soils: II. Uptake of Cd, Ni and Zn in rice plants grown under flooded culture with organic matter addition. Nutr. Cycl. Agroecosys. 2001, 61, 257-266.

31. Jung, M.C.; Thornton, I. Environmental contamination and seasonal variation of metals in soils, plants and waters in the paddy fields around a $\mathrm{Pb}-\mathrm{Zn}$ mine in Korea. Sci. Total Environ. 1997, 198, 105-121.

32. Cheng, D.W.; Zhang, G.P.; Yao, H.G.; Wu, W.; Tang, M.L.; Zhu, Z.J.; Xu, M. Genotypic and environmental variation and their stability of $\mathrm{As}, \mathrm{Cr}, \mathrm{Cd}, \mathrm{Ni}$ and $\mathrm{Pb}$ concentrations in the grains of Japonica Rice. Acta Agromomica Sinca 2006, 32, 572-579.

33. Zeng, F.R.; Mao, Y.; Cheng, W.D.; Wu, F.B.; Zhang, G.P. Genotypic and environmental variation in chromium, cadmium and lead concentrations in rice. Environ. Pollut. 2008, 153, 309-314.

34. Facchinelli, A.; Sacchi, E.; Mallen, L. Multivariate statistical and GIS-based approach to identify heavy metal sources in soil. Environ. Pollut. 2001, 114, 313-324.

35. Martín, J.A.R.; Arias, M.L.; Grau Corbí, J.M. Heavy metals contents in agricultural topsoils in the Ebro basin (Spain): Application of the multivariate geostatistical methods to study spatial variations. Environ. Pollut. 2006, 144, 1001-1012.

36. Sadeghi, A.; Graff, C.D.; Starr, J.; Mccarty, G.; Codling, E.; Sefton, K. Spatial variability of soil phosphorous levels before and after poultry litter application. Soil. Sci. 2006, 171, 850-857.

37. Fu, W.; Zhao, K.; Jiang, P.; Ye, Z.; Tunney, H.; Zhang, C.S. Field-scale variability of soil test phosphorus and other nutrients in grasslands under long-term agricultural managements. Soil Res. 2013, 51, 503-512.

38. Chen, T.; Liu, X.M.; Li, X.; Zhao, K.L.; Zhang, J.B.; Xu, J.M.; Shi, J.C.; Dahlgren, R.A. Heavy metal sources identification and sampling uncertainty analysis in a field-scale vegetable soil of Hangzhou, China. Environ. Pollut. 2009, 157, 1003-1010.

39. Webster, R.; Oliver, M.A. Statistical Methods in Soil and Land Resource Survey; Oxford University Press: London, UK, 1990.

40. Burgos, P.; Madejón, E.; Pérez-de-Mora, A.; Cabrera, F. Spatial variability of the chemical characteristics of a trace-element-contaminated soil before and after remediation. Geoderma 2006, $130,157-175$. 
41. Goodchild, M.F.; Parks, B.O.; Steyaret, L.T. Environmental Modelling with GIS; Oxford University Press: New York, NY, USA, 1993.

42. Statistical Bureau of Huzhou. Huzhou Yearbook; China Statistics Press: Beijing, China, 2011. (In Chinese)

43. Wu, C.F.; Luo, Y.M.; Zhang, L.M. Variability of copper availability in paddy fields in relation to selected soil properties in Southeast China. Geoderma 2010, 156, 200-206.

44. Ma, L.Q.; Rao, G.N. Chemical fractionation of cadmium, copper, nickel, and zinc in contaminated soils. J. Environ. Qual. 1997, 26, 259-264.

45. Basta, N.T.; Ryan, J.A.; Chaney, R.L. Trace element chemistry in residual-treated soil: Key concepts and metal bioavailability. J. Environ. Qual. 2005, 34, 49-63.

(C) 2015 by the authors; licensee MDPI, Basel, Switzerland. This article is an open access article distributed under the terms and conditions of the Creative Commons Attribution license (http://creativecommons.org/licenses/by/4.0/). 